\title{
Modeling of agglomerates formation and evolution at combustion of aluminized propellants in intra-chamber environments
}

\author{
Valery A. Babuk ${ }^{1, *}$, Alexander A. Nizyaev ${ }^{1}$ \\ ${ }^{1}$ Baltic State Technical University "VOENMEH”, 190000 Saint Petersburg, Russia
}

\begin{abstract}
In the present paper, the solution of the problem of agglomerates parameters calculation in combustion chamber environments is described. For this, a method of two-dimensional axisymmetric multiphase quasistationary flow calculation has been developed. The method uses previously developed models of agglomerates formation and their evolution within multiphase flow with considering of interactions between agglomerates and gaseous combustion products. Parametric study of the developed models with respect to intra-chamber environments has been performed.
\end{abstract}

\section{Introduction}

Agglomeration (enlargement of condensed combustion products within surface layer of burning propellant) is one of phenomena at aluminized propellant burning. The resulting agglomerates can significantly exceed in size initial Al particles. Agglomerates consist of $\mathrm{Al}, \mathrm{Al}_{2} \mathrm{O}_{3}$ and have a complex structure including metal and oxide drops as well as gaseous cavities. Agglomerates represent coarse fraction of condensed combustion products. Another, fine fraction of condensed combustion products is represented by smoke oxide particles (SOP).

Within a multiphase flow, the evolution of agglomerates is carried out resulting in formation of final composition of combustion products. The evolution is understood as a set of physical and chemical phenomena that lead to changing of sizes, chemical composition, structure and mass fraction of agglomerates. As a result of the evolution, the coarse fraction of final condensed combustion products is formed.

The main features of agglomerates evolution in combustion chamber are multidimensional nature of multiphase flow, distributed inflow of agglomerates and gaseous products, mutual influence of agglomerates evolution and properties of gas flow.

Presence of agglomerates has significant influence on processes associated with slag accumulation, thermal and chemical erosion, and pressure oscillations. In that regard, the problem of numerical simulation of agglomerates formation and evolution is relevant. This led to appearance of a large number of works dedicated to modeling of agglomerates

* Corresponding author: babuk@peterlink.ru 
formation [1]. A significant number of works is devoted to numerical simulations of multiphase flows containing agglomerates, for example works [2-4] and others.

In the present work, previously developed models of agglomerates formation $[5,6]$ and their evolution [7] are used for calculation of agglomerates parameters. The main feature of these models is the ability to calculate not only sizes and mass fraction of agglomerates but also chemical composition and structure parameters. Below the developed method for usage of the models in intra-chamber conditions is presented with attention focused on multidimensional nature of flow and influence of agglomerates evolution on properties of gaseous phase.

\section{Calculation of agglomerates parameters}

\subsection{Agglomerates parameters on surface of burning propellant}

The agglomeration model $[5,6]$ can be used to determine the properties of emerging agglomerates at burning propellant surface. The model is based on considering of agglomeration regularities depending on propellant type, modeling of initial propellant structure, and modeling of evolution of enlarging agglomerating particles on propellant surface. The model allows determining the following main agglomerates characteristics:

- $\quad f_{\mathrm{m}}(D)$ - mass function of size distribution density of agglomerates;

- $\quad D_{43}$ - mass-medium size of agglomerates, $\mu \mathrm{m}$;

- $\quad Z_{\mathrm{m}}^{\mathrm{a}}-$ fraction of initial metal used to form agglomerates;

- $\quad \eta$ - mass fraction of $\mathrm{Al}_{2} \mathrm{O}_{3}$ in agglomerates;

- Parameters of agglomerates structure.

Input data of the model are the type and mass fraction of propellant components, sizes of oxidizer particles in propellant, operating conditions (pressure, acceleration).

\subsection{Agglomerates parameters within multiphase flow of combustion products}

The model of agglomerates evolution [7] can be used for calculating of agglomerates parameters within multiphase flow. The model is based on the description of following phenomena:

- $\quad$ Burning of $\mathrm{Al}$ in gas-phase mode;

- Chemical interaction between condensed $\mathrm{Al}$ and $\mathrm{Al}_{2} \mathrm{O}_{3}$ resulting in formation of gaseous products;

- Agglomerates structure changes;

- $\quad$ Coagulation of agglomerates and SOP;

- $\quad$ Agglomerates movement within the flow.

Agglomerates evolution simulation consists in integrating of the ordinary differential equations describing movement and changes in parameters of single agglomerates at time. The model allows determining the changes in agglomerates parameters from the moment of agglomerates detachment from propellant surface until they hit the chamber walls or enter into a nozzle.

\subsection{Agglomerates evolution modeling in intra-chamber environments}

The gaseous phase and SOP cloud are considered as a continuum with parameters determined using Eulerian approach while agglomerates parameters are described using discrete trajectories according to Lagrangian approach. Such method was used in works 
$[3,4]$. As the input data the geometric parameters of combustion chamber and grain, propellant composition and burning rate, and agglomerates initial parameters are used.

\subsubsection{Modeling of gaseous phase flow}

Numerical simulation of gaseous flow is carried out by solving the Navier-Stokes and continuity equations of uncompressible viscous fluid in stationary conditions. Gas properties are assumed to be a constant. The flow is assumed to be laminar and axisymmetric. Boundary conditions are determined by geometric parameters of calculation domain, mass flux of gas supply, and pressure in outlet region. Mass flux $\left(\mathrm{kg} / \mathrm{m}^{2} / \mathrm{s}\right)$ of gas supply at propellant surface is determined by gasification of propellant components:

$$
m_{\mathrm{g}}=u_{\mathrm{p}}\left\{1-z_{\mathrm{m}}^{\mathrm{p}}\left[\frac{2 \mu_{\mathrm{Al}}+3 \mu_{\mathrm{O}}}{2 \mu_{\mathrm{Al}}}\left(1-Z_{\mathrm{m}}\right)+Z_{\mathrm{m}}\right]\right\} / \sum_{n} \frac{z_{n}}{\rho_{n}}
$$

where $u_{\mathrm{p}}$ - linear burning rate of propellant grain, $\mathrm{m} / \mathrm{s} ; z_{\mathrm{m}}^{\mathrm{p}}-$ mass fraction of $\mathrm{Al}$ in propellant; $\mu_{\mathrm{Al}}, \mu_{\mathrm{O}}-$ molar masses of elements $\mathrm{Al}$ and $\mathrm{O} \mathrm{kg} / \mathrm{mole} ; Z_{\mathrm{m}}$ - ratio between unburned $\mathrm{Al}$ in agglomerates and initial $\mathrm{Al}$ in propellant; $z_{n}, \rho_{n}-$ mass fraction and density of $n$-th propellant component. Pressure in outlet section is determined by operating conditions.

\subsubsection{Determination of agglomerates parameters in computational domain}

The agglomerates parameters are determined using the discrete trajectory approach. According to this, the agglomerates phase is represented by set of discrete particles. The problem of agglomerates evolution modeling is solved by calculation of agglomerates trajectories and determining of agglomerates parameters along the trajectories. Herewith the continuous function $f_{\mathrm{m}}(D)$ is sampled for a several fractions with agglomerates sizes $D_{i}$ and corresponding mass fractions $z_{i}$, where $i$ - fraction number. Propellant surface is sampled for a several fragments from which agglomerates of all fractions are injected. Thus the mass flow $(\mathrm{kg} / \mathrm{s})$ of agglomerates of $i$-th size fraction from $j$-th propellant fragment is determined by equation:

$$
M_{\mathrm{a} i, j}=u_{\mathrm{p}} \cdot \rho_{\mathrm{p}} \cdot z_{\mathrm{m}}^{\mathrm{p}} \cdot Z_{\mathrm{m}}^{\mathrm{a}} \cdot z_{i} \cdot F_{j}\left[1+\frac{3 \mu_{\mathrm{O}} \cdot \eta}{2 \mu_{\mathrm{Al}}+3 \mu_{\mathrm{O}} \cdot(1-\eta)}\right],
$$

where $\rho_{\mathrm{p}}$ - propellant density, $\mathrm{kg} / \mathrm{m}^{3} ; F_{j}$-area of $j$-th propellant fragment, $\mathrm{m}^{2}$. As results of evolution modeling are the dependencies of agglomerates parameters including coordinates on time for each $i, j$-th agglomerate (of $i$-th size fraction injected from $j$-th propellant surface fragment).

\subsubsection{Computational domain sampling}

The sampling of computational domain is performed by creation of curved mesh connected with streamlines of gaseous phase flow. A cell of such mesh is represented by a stream tube. Within the each cell, a curvilinear coordinate system is constructed. Axis of such coordinate system is coincident with a streamline. Origin of the coordinate system 
corresponds to the surface of propellant grain. Analysis of agglomerates trajectories allows obtaining dependencies of agglomerates parameters on curvilinear coordinates, figure 1.

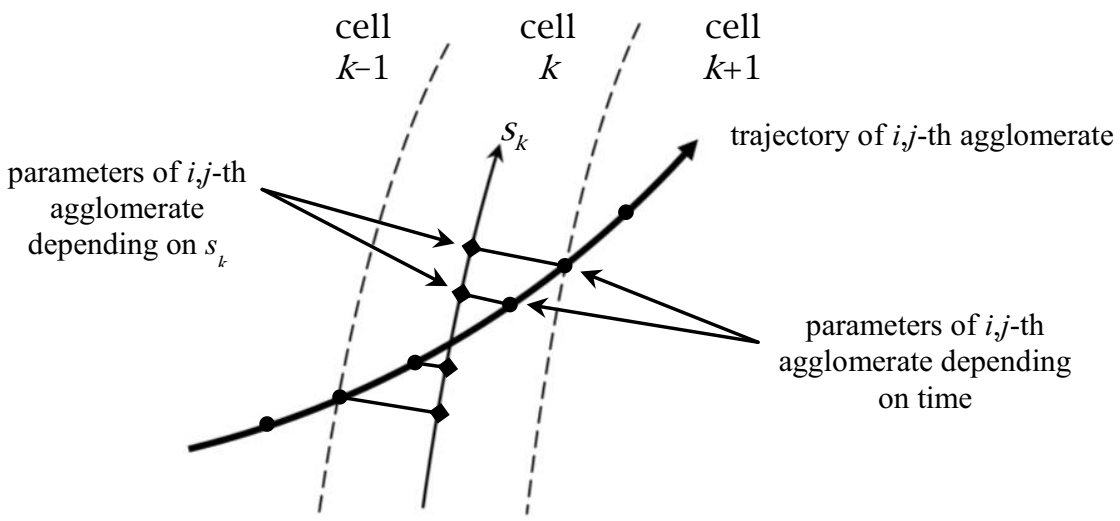

Fig. 1. Cell and curvilinear axis of computational domain.

While agglomerate appears within $k$-th cell, the projection of its parameters on corresponding curvilinear axis $s_{k}$ is performed. Thus, parameters of each $i, j$-th agglomerate are determined as functions of curvilinear coordinates. Interpolation of parameters between adjacent axes allows determining the fields of agglomerates parameters in rectangular coordinate system. In other words, this procedure allows determining the parameters of agglomerates cloud using Eulerian approach.

\subsubsection{Calculation of parameters of combustion products mixture}

As an individual mixture components, the 22 species including compounds of elements $\mathrm{C}$, $\mathrm{H}, \mathrm{O}, \mathrm{N}, \mathrm{Cl}, \mathrm{Al}$ are considered. The mixture parameters are calculated assuming thermodynamic equilibrium state of gaseous and condensed products excluding unburned $\mathrm{Al}$ in agglomerates. The evolution of agglomerates leads to decrease of fraction of unburned $\mathrm{Al}$ in agglomerates and to increase of $\mathrm{Al}$ combustion completeness. The combustion completeness of $\mathrm{Al}$ is characterized by parameter $X_{\mathrm{m}}$ - ratio between mass of burnt $\mathrm{Al}$ and mass of initial $\mathrm{Al}$ within the considering computational cell. It allows representing the mixture parameters (temperature, composition, mass and heat transfer properties) as functions of parameter $X_{\mathrm{m}}$.

Within the $k$-th computational cell the function $X_{\mathrm{m}}\left(s_{k}\right)$ is determined by equations:

$$
\begin{gathered}
X_{\mathrm{m}}\left(s_{k}\right)=1-Z_{\mathrm{m}}+\sum_{i} \sum_{j}\left(M_{\mathrm{m}_{i, j}}^{0}-M_{\mathrm{m}_{i, j}}\left(s_{k}\right)\right) / M_{\mathrm{m} k}, \\
M_{\mathrm{m}_{i, j}}=\left(1-\eta_{i, j}\right) M_{\mathrm{a} i, j}, \\
M_{\mathrm{m} k}=u_{\mathrm{p}} \cdot \rho_{\mathrm{p}} \cdot z_{\mathrm{m}}^{\mathrm{p}} \cdot F_{k},
\end{gathered}
$$

where $M_{\mathrm{m} i, j}^{0}$ - mass flow of unburned $\mathrm{Al}$ of $i, j$-th agglomerate at its entry into $k$-th cell, $\mathrm{kg} / \mathrm{s} ; F_{k}$ - propellant surface area in the base of $k$-th cell, $\mathrm{m}^{2}$. Interpolation of values of $X_{\mathrm{m}}$ between cell axes allows determining the mixture parameters using Eulerian approach.

The calculation continues through global iterations on which sequential recalculations of the fields of gaseous phase and agglomerates parameters are performed. The calculation 
ends at achievement of required accuracy of $X_{\mathrm{m}}$ at several control points within computational domain.

\section{Results}

Parametric study was performed applying to a combustion chamber with axisymmetric shape of propellant grain. Geometric parameters of the grain corresponded to the working time $15 \mathrm{~s}$. Total burning surface area at this time was 6.71 square meters. Operating pressure was 6.0 MPa. Propellant parameters were: $z_{\mathrm{m}}^{\mathrm{p}}=0.24 ; u_{\mathrm{p}}=8.1 \mathrm{~mm} / \mathrm{s}$, $\rho_{\mathrm{p}}=1830 \mathrm{~kg} / \mathrm{m}^{3}$; agglomerates parameters were: $D_{43}=250 \mu \mathrm{m}, \eta=0.4, Z_{\mathrm{m}}^{\mathrm{a}}=0.344$ [8].

On the figure 2, the stream lines of gaseous phase and trajectories of agglomerates with initial sizes $50 \mu \mathrm{m}$ and $250 \mu \mathrm{m}$ are presented. On the figure the sections corresponding to propellant surface (A-B), chamber wall (B-C) and outlet section (C-D) are presented.

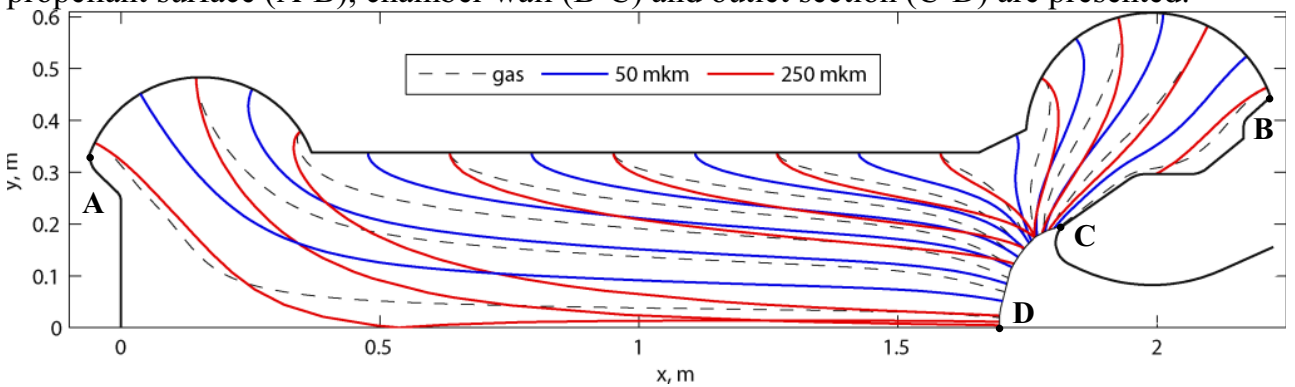

Fig. 2. Gas streamlines and agglomerates trajectories.

On the figure 3, the functions $f_{\mathrm{m}}(D)$ at sections A-B, B-C, and C-D are presented. Also agglomerates mass flows $\left(M_{\mathrm{a}}\right)$ and values of $\eta$ at these sections are indicated. It should be noted that values of $M_{\mathrm{a}}$ and $\eta$ at section B-C can be used for estimation of slag accumulation rate and its composition.

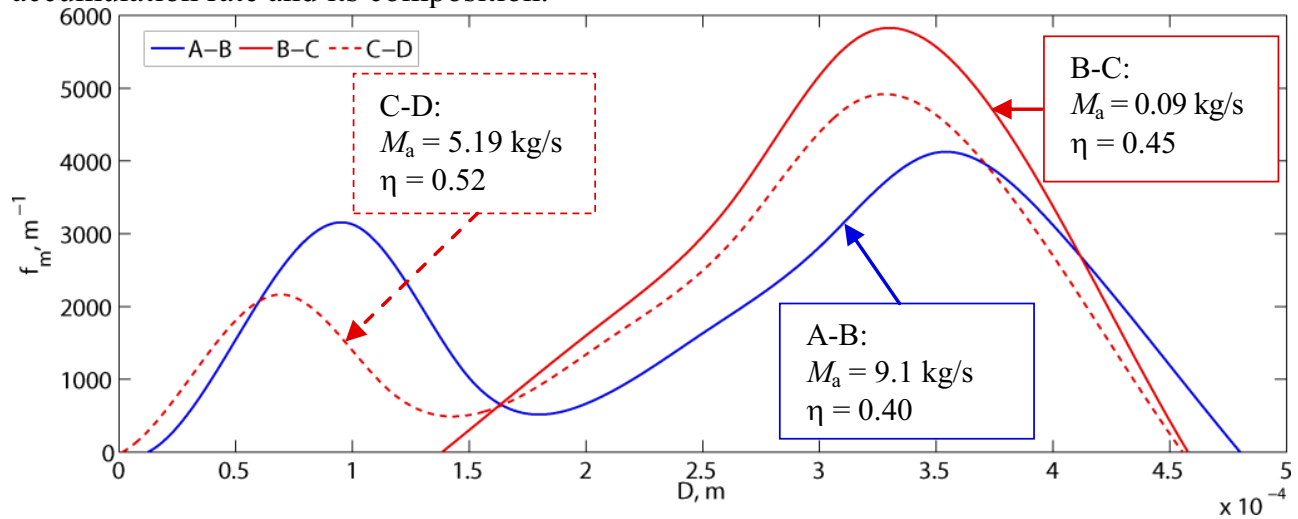

Fig. 3. Size mass density distribution function of agglomerates at sections A-B, B-C, and C-D.

The figure 4 represents the temperature field of combustion products mixture excluding agglomerates. 


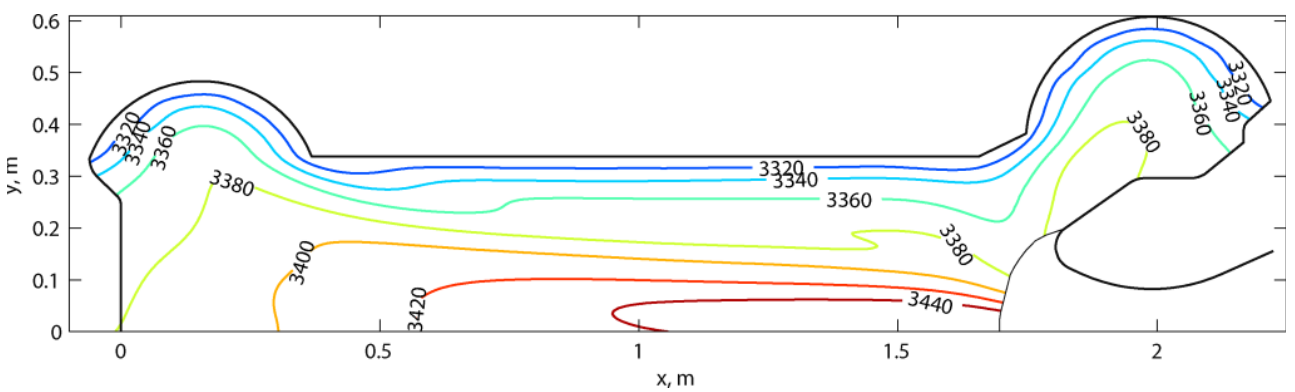

Fig. 4. Temperature field of gaseous phase and SOP.

Analysis of modeling results allows making conclusions about influence of agglomerates evolution on parameters of agglomerates and gaseous combustion products. Herewith determining of $\mathrm{Al}$ combustion completeness, as well as estimating of slag accumulation rate is possible. Correctness of calculated parameters of agglomerates is provided by usage of the agglomerates evolution model which was verified by experimental study results [7].

\section{Conclusions}

The usage of the models of agglomerates formation and evolution was considered. The method for calculation of agglomerates and gaseous phase parameters was described. Interactions between evolution process of agglomerates and gaseous phase properties as well as two-dimensional multiphase flow aspects were taken into account. Results of performed parametric study allowed to make conclusion about possibility of usage of developed models in intra-chamber conditions.

\section{References}

1. M.W. Beckstead, Proc. of 50th Annual Israeli Aerospace Sciences Conference (Tel Aviv, 2010)

2. J. Dupays, Y. Fabignon, P. Villedieu, G. Lavergne, J.L. Estivalezes, Prog. Astronautics Aeronautics, 185, 859 (2000)

3. T. Shimada, Y. Daimon, N. Sekino, Proc. of the $8^{\text {th }}$ International Symposium on Experimental and Computational Aerothermodynamics of Internal Flows, July 2007, Lyon, France, paper ISAIF8-00109 (2007)

4. A. Attili, B. Favini, M.Di Giacinto, 45th AIAA/ASME/SAE/ASEE Joint Propulsion Conference \& Exhibit 2 - 5 August 2009, Denver, Colorado, 5507 (2009)

5. V.A. Babuk, I.N. Dolotkazin, A.A. Nizyaev, Progress in Propulsion Physics, 4, 33 (EDP Sciences, Torus Press, 2013)

6. V.A. Babuk, A.N. Ivonenko, A.A. Nizyaev, Combust., Expl., Shock Waves, 51 (5), 549(2015)

7. V.A. Babuk, V.A. Vasilyev, J. Propul. Power, 18 (4), 814 (2002)

8. V.A. Babuk, V.A. Vasilyev, M.S. Malakhov, J. Propul. Power, 15 (6), 783 (1999) 